\title{
VIABILIDADE TÉCNICA E ECONÔMICA DO CULTIVO DE SAFRINHA DO GIRASSOL IRRIGADO NA REGIÃO DE LAVRAS, MG'
}

\author{
Technical and economic viability of the cultivation of late summer cultivation period \\ of the sunflower irrigation in the Lavras, MG region
}

\author{
Mirian de Lourdes Oliveira e Silva ${ }^{2}$, Manoel Alves de Faria ${ }^{3}$, Ricardo Pereira Reis ${ }^{4}$, \\ Márcio José de Santana ${ }^{5}$, Wesley Mattioli ${ }^{6}$
}

\begin{abstract}
RESUMO
Por meio deste estudo de viabilidade técnica-econômica utilizou-se os dados experimentais obtidos na Universidade Federal de Lavras (UFLA), no período de março a julho de 2004, com o objetivo de avaliar as eficiências técnicas e econômicas do cultivo do girassol na região de Lavras, MG, no período de safrinha, em duas situações distintas, sendo uma na condição que o produtor não possui o sistema de irrigação (não irrigante) e outra que o produtor é irrigante e quer decidir de que forma deve conduzir a lavoura. Os dados utilizados foram provenientes de experimentos conduzidos com os tratamentos de lâminas de água referentes à reposição pela irrigação, de 75, 100 e 130\% da evapotranspiração estimada para a cultura, num intervalo de dois dias (turno de rega fixo) e a testemunha que não era irrigada, correspondendo, respectivamente, às lâminas de água recebida de 350,84 $\mathrm{mm}, 428,70,522,14$ e 117,20 $\mathrm{mm}$. Os dados usados na análise foram a produtividade do girassol obtida nos experimentos e os custos da lavoura nas duas condições anteriormente citadas. Para o caso da lavoura irrigada, considerou-se como sistema de irrigação o pivô central e a estimativa dos custos da lavoura foi baseada na teoria dos custos de produção. Os resultados mostraram que houve eficiência técnica, uma vez que a produtividade média para a situação não irrigada (117,2 mm de chuva) foi de 1924,27 $\mathrm{kg} \mathrm{ha}^{-1} \mathrm{e}$ para a situação de irrigação de 2293,15 $\mathrm{kg} \mathrm{ha}^{-1}, 2564,26 \mathrm{~kg} \mathrm{ha}^{-1} \mathrm{e} 2863,12 \mathrm{~kg} \mathrm{ha}^{-1}$, respectivamente para as lâminas de água correspondentes de 350,84, 428,70 e 522,14 mm. Na situação econômica analisada, cujo preço da saca de girassol considerado foi de $\mathrm{R} \$ 31,80$ (junho/2004), recomenda-se para o produtor irrigante a aplicação da lâmina de 522,14 mm de água ao longo do ciclo, mas a persistir tal situação, o produtor poderá entrar em um processo de descapitalização, não repondo parte do capital fixo, tendo que optar por outra alternativa de mercado.
\end{abstract}

Termos para indexação: Girassol, irrigação, análise econômica.

\begin{abstract}
This study was to verify the technical and economical viability for experimental data of sunflower growth obtained in the Federal University of Lavras (UFLA), during period from March to June of 2004, in two different situations: irrigated and non-irrigated field. The used data came from several experiments carried out with three treatments of irrigation water depth replacement of 75, 100 and $130 \%$ of the evapotranspiration, estimated for the crop in an interval of two days (fixed irrigation interval) and a control plot, that was not irrigated. The corresponding irrigation water depths were: $350.84,428.70,522.14$ and $117.20 \mathrm{~mm}$. The productivity of the sunflower crop and the costs of the fieldwork were evaluated in both mentioned conditions. It was considered, for the case of the irrigated crop, the central pivot irrigation system and the estimated cost of the fieldwork was based on the theory of "Cost of Production". The results showed technical efficiency, since the average productivity for the non-irrigated situation $\left(117,2 \mathrm{~mm}\right.$ of rain) was of $1924.27 \mathrm{~kg} \mathrm{ha}^{-1}$, while for the irrigated condition the productivity was $2293.15,2564.26$ and $2863.12 \mathrm{~kg} \mathrm{ha}^{-1}$, respectively, for the irrigation water depth of $350,84,428,70$ and $522,14 \mathrm{~mm}$. In the analyzed economical situation, with the considered price, for sunflower, of R $\$ 31,80$ per bag of $60 \mathrm{~kg}$ (June/ 2004), it is recommended application of $522,14 \mathrm{~mm}$ of irrigation water depth along the cycle. In the case of persisting such circumstance, the farmer may undergo into a descapitalization process, not replacing part of the fixed capital, having to decide for another market alternative.
\end{abstract}

Index terms: Sunflower, irrigation, economic analysis.

(Recebido para publicação em 31 de janeiro de 2006 e aprovado em 1 de agosto de 2006)

${ }^{1}$ Parte da tese de doutorado desenvolvida pela primeira autora.

${ }^{2}$ Engenheira Agrícola, doutora em Engenharia Agrícola/Irrigação e Drenagem, Departamento de Engenharia da Universidade Federal de Lavras/UFLA Cx. P. 3037 - 37200-000 - Lavras, MG - misilva@ufla.br

3Professor Titular, Departamento de Engenharia da Universidade Federal de Lavras/UFLA - Cx. P. 3037 - 37200-000 - Lavras, MG - mafaria@ufla.br ${ }^{4}$ Professor Titular, Departamento de Administração e Economia da Universidade Federal de Lavras/UFLA - Cx. P. 3037 - $37200-000$ - Lavras, MG ricpreis@ufla.br

${ }^{5}$ Doutorando em Engenharia Agrícola, Departamento de Engenharia da Universidade Federal de Lavras/UFLA - Cx. P. 3037 - $37200-000$ - Lavras, MG marciodeg@uol.com.br

${ }^{6}$ Mestrando em Engenharia Agrícola, Departamento de Engenharia da Universidade Federal de Lavras/UFLA - Cx. P. 3037 - $37200-000$ - Lavras, MG mattioli@vialavras.com.br 


\section{INTRODUÇÃO}

O girassol (Helianthus annuus L.) está entre as cinco maiores culturas oleaginosas produtoras de óleo vegetal comestível $(6,5 \%$ da produção mundial de oleaginosas na safra 2001/2002), ficando atrás apenas da soja $(56,8 \%$ do total), do algodão (11,3\% do total), da colza (11,1\% do total) e do amendoim $(10,23 \%$ do total $)$ (FAGUNDES, 2002).

O Brasil é um produtor pouco expressivo de girassol (grão), tendo participado com aproximadamente $0,5 \%$ da produção mundial nos últimos anos (FAGUNDES, 2002).

A produção de girassol (grão) no Brasil concentrase nas regiões Centro-Oeste (Goiás e Mato Grosso do Sul, com $45,6 \%$ e $23,8 \%$, respectivamente, da produção na safra 2004), Sul (Rio Grande do Sul, com $11,7 \%$ da produção na safra 2004) e Sudeste (São Paulo, com 3,5\% da produção na safra 2004), segundo Agrianual (2005).

O girassol é uma cultura que apresenta características desejáveis sob o ponto de vista agronômico, tais como: ciclo curto, elevada qualidade e bom rendimento em óleo, o que o qualifica como uma boa opção aos produtores brasileiros. E ainda, com o incentivo do governo Federal, mais recentemente, em utilizar o biodiesel na matriz energética nacional, através de sua adição ao óleo diesel comercializado, a cultura do girassol apresenta viabilidade técnico-ambiental na produção de biocombustíveis.

No Sudeste, o cultivo do girassol, em sucessão a grandes culturas, tem-se mostrado uma boa alternativa para o agricultor, permitindo o aproveitamento de áreas irrigadas ou não, na entressafra e de reforma de canavial, na safra, ou mesmo áreas tradicionais (GOMES et al., 2003). O girassol além de permitir a obtenção de grãos para produção de óleo na entressafra, diminui a capacidade ociosa das indústrias, otimizando a utilização da terra, máquinas e mão-de-obra.

Segundo Silva (1990), a região Sul do Estado de Minas Gerais é considerada, dentro da faixa de potencialidade climática para a cultura do girassol, apta para dois cultivos anuais complementares de girassol no mesmo terreno.

Experimentos têm mostrado que as melhores respostas obtidas de produtividade do girassol, associam a irrigação e adubação adequada (UNGARO, 1990).

Os autores deste trabalho acreditam que a irrigação é uma prática que, além de incrementar a produtividade, pode proporcionar a obtenção de um produto de melhor qualidade e com perspectiva de bons preços no mercado. Porém, a perspectiva promissora da adoção da irrigação deve ser estudada e analisada de forma detalhada no que se refere ao planejamento, dimensionamento, manejo e desenvolvimento da cultura. Também acreditam que a irrigação pode ajudar muito os agricultores, porém, os riscos da adoção de uma agricultura irrigada devem ser criteriosamente planejada, objetivando sempre que a receita líquida seja maior que os custos.

Determinar a viabilidade de um empreendimento que se inicia é fundamental para o seu sucesso. A irrigação é uma tecnologia que requer investimentos representativos e está associada à utilização intensiva de insumos, tornando importante a análise econômica dos componentes envolvidos no sistema.

O custo da irrigação pode ser previsto por meio de uma avaliação econômica na qual se estimam todos os dispêndios e retornos anuais esperados no projeto agrícola. O resultado dessa avaliação econômica irá mostrar se é interessante ou não a implantação de um sistema de irrigação.

Em função do exposto, por meio deste trabalho, busca-se avaliar técnica e economicamente o cultivo do girassol irrigado, no período de safrinha, na região de Lavras, Sul de Minas Gerais.

\section{MATERIAL E MÉTODOS}

Para este estudo de viabilidade, usou-se dados experimentais obtidos na Universidade Federal de Lavras (UFLA), localizada a $21^{\circ} 14^{\prime} 06^{\prime \prime}$ de latitude sul e $45^{\circ} 00^{\prime} 00^{\prime}$ " de longitude oeste, a uma média de $918 \mathrm{~m}$ de altitude (CASTRO NETO \& SILVEIRA, 1983), durante o período de março a julho de 2004.

Foram utilizadas duas cultivares de girassol (Helianthus annuus L.); sementes dos híbridos Hélio 250 (H250) e Hélio 251 (H251), semeadas no espaçamento de $0,8 \mathrm{~m}$ entre linhas, com uma população de 62500 plantas/ ha, provenientes de experimentos conduzidos com os tratamentos de lâmina de água referentes à reposição pela irrigação, de 75, 100 e $130 \%$ da evapotranspiração estimada para a cultura, num intervalo de dois dias (turno de rega fixo) e a testemunha que só recebia a água de chuva e que, portanto, não era irrigada.

Os dados usados na análise foram a produtividade do girassol obtido nos experimentos e os custos da irrigação para aplicar lâminas de água semelhante às experimentais, usando-se um equipamento de pivô central com propulsão elétrica, 7 torres acionadoras, alcance total de 378,42 m e área circular irrigada de 44,99 ha.

Utilizou-se para a estimativa do custo de produção, o procedimento econômico, em que se considera o cálculo da depreciação e do custo alternativo (REIS, 2002). O custo 
necessário para substituir os bens de capital quando tornados inúteis, seja pelo desgaste físico ou econômico foi definido como a depreciação (D). O método utilizado foi o linear, referente a um tempo de cinco meses $(0,42$ anos), equivalente ao ciclo médio da cultura do girassol, mensurado pela expressão (1):

$$
\mathrm{D}=\frac{\mathrm{V}_{\mathrm{a}}-\mathrm{V}_{\mathrm{r}}}{\mathrm{V}_{\mathrm{u}}} * 0,42 \text { anos }
$$

em que: $\mathrm{D}=$ depreciação, $\mathrm{V}_{\mathrm{a}}=$ valor atual do recurso, $\mathrm{V}_{\mathrm{r}}=$ valor residual $\mathrm{e} \mathrm{V}_{\mathrm{u}}=$ vida útil.

Para efeito da análise do custo alternativo fixo (CAfixo) dos recursos produtivos alocados no cultivo do girassol, considerou-se a taxa de juros real de $12 \%$ a.a. No seu cálculo utilizou-se a expressão (2):

$$
\mathrm{CA}_{\text {fixo }}=\frac{\mathrm{V}_{\mathrm{a}}}{2} * \text { taxa de juros } * 0,42 \text { anos }
$$

Para o cálculo do custo alternativo variável $\left(\mathrm{CA}_{\mathrm{var}}\right)$ usou-se a expressão (3), considerando-se a taxa de juros real de $12 \%$ a.a.:

$$
\mathrm{CA}_{\text {var }}=\mathrm{V}_{\text {gasto }} * \text { taxa de juros } * 0,42 \text { anos }
$$

O custo de cada recurso fixo foi calculado somandose a depreciação e o custo alternativo do fator produtivo. Os itens considerados para os custos fixos foram: máquinas e implementos, ITR e sistema de irrigação. Como neste trabalho o objetivo foi o cultivo de uma cultura de inverno (período da safrinha), partiu-se do pressuposto que o proprietário (dono da atividade a ser explorada) já possuia como lavoura principal, outra cultura cultivada no verão (período de safra), sendo que os itens terra e formação de lavoura não foram considerados nos custos fixos.

O custo de cada recurso variável foi calculado pelo desembolso realizado para aquisição de produtos e serviços somado ao custo alternativo. Os itens considerados para os custos variáveis foram: combustíveis, lubrificantes, conservação e reparos das máquinas e implementos; despesas com mão-de-obra permanente e temporária; insumos (calagem, sementes, fertilizantes, fungicidas, inseticidas, herbicidas, etc.); despesas gerais com administração e pós-colheita; energia elétrica e água.

Utilizou-se para o cálculo dos custos de máquinas e implementos a forma de rateio, que consiste na distribuição do valor de um recurso fixo para as atividades agrícolas que são desenvolvidas na empresa agrícola, desde que este recurso não seja específico para a atividade.
Neste trabalho a forma de rateio utilizada para o cálculo dos custos de máquinas e implementos foi com base no tempo proporcional de utilização destes recursos pela atividade do girassol e o critério adotado para correção de valores foi o de preço único, somando-se as quantidades utilizadas durante o ciclo da cultura do girassol, corrigidas pelo preço médio. Para esta análise considerou-se o preço do girassol em $\mathrm{R} \$ 31,80$ por saca de $60 \mathrm{~kg}$, conforme apresentado em Agrianual (2005).

Utilizou-se também para a análise, o cálculo do custo alternativo ou de oportunidade e custo operacional (Cop) e para facilitar as análises em termos unitários, apuraramse os custos médios (CMe). Os custos operacionais constituíram-se nos valores correspondentes às depreciações e aos insumos empregados, equivalentes ao prazo de análise e os custos alternativos corresponderam à remuneração que esses recursos teriam se fossem empregados na melhor das demais alternativas econômicas possíveis (REIS, 2002).

O custo econômico foi obtido da soma entre o custo operacional e do custo alternativo. $\mathrm{O}$ custo operacional foi dividido em custo operacional fixo (CopF), composto pelas depreciações e custo operacional variável (CopV), constituído pelos desembolsos. O custo operacional total (CopT) constituiu-se da soma do custo operacional fixo e operacional variável. A finalidade dos custos operacionais na análise é a opção de decisão em casos em que os retornos financeiros sejam inferiores ao de outra alternativa, representada pelos custos de oportunidade. Neste sentido, ainda podem fazer importantes interpretações com base neste tipo de custo (REIS, 2002).

Dessa forma, este trabalho apresenta um diagnóstico do comportamento econômico-financeiro do cultivo do girassol no período da safrinha, com informações a respeito da remuneração obtida, da cobertura dos recursos de curto (custos variáveis) e longo (custos fixos) prazos e comparações entre a remuneração obtida pela atividade produtiva e àquela que seria proporcionada por outras alternativas (custos alternativos).

Este estudo estimou a viabilidade do cultivo de girassol, no período da safrinha, em duas situações:

a) Situação (1): o produtor possuia uma atividade principal (cultivo de safra) e não possuia um sistema de irrigação;

b) Situação (2): o produtor possuia uma atividade principal (cultivo de safra) e possuia um sistema de irrigação, mas precisava decidir se utilizava o sistema de irrigação no cultivo do girassol, ou, cultivava-o do modo convencional (sem irrigação). 


\section{RESULTADOS E DISCUSSÃO}

Os dados relativos à produtividade de grãos do girassol estão apresentadas na Tabela 1. Com base nesta informação pode ser observado um aumento relativo na produtividade, em kg/ha, dos grãos de girassol, em função das lâminas de água aplicadas, sendo que para a lâmina de $522,14 \mathrm{~mm}$, referente à reposição de $130 \%$ da evapotranspiração estimada da cultura (Etc), a produtividade chegou a $2863,12 \mathrm{~kg} \mathrm{ha}^{-1}$. O incremento médio verificado na produtividade foi da ordem de 19,17 , 33,26 e 48,79\% para as lâminas de água aplicadas de 350,84 $\mathrm{mm}$ (75\% Etc), 428,70 mm (100\% Etc) e 522,14 mm (130\% Etc), respectivamente, comparados à lâmina de 117,20 mm, correspondente à condição que não era irrigado. Tais incrementos foram semelhantes aos encontrados por Gomes et al. (2005).

Com base nesses resultados pode-se afirmar que houve eficiência técnica na produção, uma vez que, mesmo sem irrigação, a produtividade média foi de $1924,27 \mathrm{~kg}$ ha ${ }^{1} \mathrm{e}$, na condição irrigada, houve aumento desta produtividade chegando aos $2863,20 \mathrm{~kg} \mathrm{ha}^{-1}$, para a lâmina de 522,14 mm (130\% Etc) aplicada no ciclo da cultura.

Estes resultados foram melhores do que os encontrados por Embrapa (2003a, b), Silva, A. et al. (2005) e Silva, M. et al. (2005) para as mesmas cultivares em regiões já recomendadas pela pesquisa, como produtora de girassol na safrinha.

Na Tabelas 2 apresenta-se os custos médios calculados para a produção de girassol, nas diferentes condições de condução da cultura.

Observa-se que, para a situação (1), a lâmina de água de 117,20 mm (chuva) apresenta o menor custo total médio (CTMe), ocorrendo o inverso para a situação (2); caso em que o produtor já possui o sistema de irrigação, mas não o usa para evitar os custos variáveis da irrigação correspondentes à energia elétrica e água. $\mathrm{O}$ custo total médio estimado para a atividade foi de $\mathrm{R} \$ 32,71 /$ saca na situação (1), enquanto que na situação (2) foi de $R \$ 43,66$ / saca, usando-se apenas a água de chuva. Nesta situação, este custo reduziu em até $\mathrm{R} \$ 37,52 /$ saca com o aumento da lâmina de água aplicada em função de sua maior produtividade. Em todas as situações o custo total médio da saca produzida é superior ao preço de venda considerado ( $\mathrm{R} \$ 31,80 /$ saca).

Com base nestes dados, verifica-se a existência de resíduo positivo para as duas situações consideradas (1) e (2), em que os custos totais médios (CTMe) de cada situação foi superior ao preço médio da saca do girassol ( $\mathrm{R} \$ 31,80 /$ saca), que por sua vez, mostrou-se superior aos custos operacionais totais médios (CopTMe). Como a remuneração é menor que a de outras formas de aplicação do capital (custo de oportunidade), o produtor de girassol nestas condições pode permanecer na atividade, apenas no curto prazo, mas com o processo de descapitalização, não repondo parte do custo fixo (depreciação), a longo prazo provavelmente irá buscar melhores alternativas de aplicação desse capital, como o mercado financeiro a taxa de juros considerada no estudo, que foi de $12 \%$ a.a.

Supondo que nesse período (safrinha) a área de cultivo ficaria ociosa (sem nenhuma outra atividade agrícola), seria vantajoso para o produtor, na situação (1), investir na atividade do girassol, pois assim ele estaria cobrindo os custos variáveis deste cultivo e parte dos custos fixos já investidos na atividade principal e ainda, haveria uma contribuição para a redução da infestação de plantas daninhas e mantendo o solo coberto favorecendo o sistema conservacionista do solo agrícola.

Na situação (2) é mais vantajoso produzir o girassol irrigado, visto que devido ao investimento já realizado com o equipamento de irrigação, o custo total médio de produção reduz-se com o aumento da lâmina de água aplicada, mostrando que o retorno observado pelo aumento de produtividade, promovido pela irrigação, é maior do que o investimento necessário na operação da mesma (energia e água); portanto, sendo vantajoso aplicar a lâmina de água correspondente a 522,14 mm no ciclo da cultura.

TABELA 1 - Média da produtividade dos grãos de girassol em função das lâminas de água. UFLA, Lavras/MG, março a junho de 2004.

\begin{tabular}{ccc}
\hline Lâminas $(\mathbf{m m})$ & Produtividade $\left(\mathbf{k g ~ h a}^{\mathbf{- 1}}\right)$ & Produtividade relativa (\%) \\
\hline 117,20 & 1924,27 & 100,00 \\
350,84 & 2293,15 & 119,17 \\
428,70 & 2564,26 & 133,26 \\
522,14 & 2863,12 & 148,79 \\
\hline
\end{tabular}


Na Tabela 3, são apresentados os itens no custo total de produção do girassol, para as duas correspondentes à participação de cada recurso produtivo situações consideradas.

TABELA 2 - Custos econômicos e operacionais médios* da produção de girassol, em R $\$$ /saca, em diferentes situações de condução da lavoura, UFLA, Lavras/MG, março a junho de 2004.

\begin{tabular}{ccccccc}
\hline Lâminas de água (mm) & CFMe & CVMe & CTMe & CopFMe & CopVMe & CopTMe \\
\hline $\begin{array}{c}\text { Situação (1): } \\
117,20\end{array}$ & 8,02 & 24,68 & 32,71 & 3,38 & 24,68 & 28,06 \\
$\begin{array}{c}\text { Situação (2): } \\
117,20\end{array}$ & 18,98 & 24,68 & 43,66 & 7,29 & 24,68 & 31,97 \\
350,84 & 15,92 & 25,42 & 41,35 & 6,12 & 25,42 & 31,54 \\
428,70 & 14,24 & 24,30 & 38,54 & 5,47 & 24,30 & 29,77 \\
522,14 & 12,75 & 24,76 & 37,52 & 4,90 & 24,76 & 29,66 \\
\hline
\end{tabular}

* CFMe = custo fixo médio; $\mathrm{CVMe}=$ custo variável médio; CTMe = custo total médio; CopFMe = custo operacional fixo médio; CopVMe = custo operacional variável médio; CopTMe = custo operacional total médio;

(1): situação em que o produtor não possui o sistema de irrigação;

(2): situação em que o produtor possui o sistema de irrigação.

TABELA 3 - Porcentagem dos custos fixos e variáveis da produção de girassol, em diferentes lâminas de água aplicadas, UFLA, Lavras/MG, março a junho de 2004.

\begin{tabular}{cccccc}
\hline Custos Fixos e Variáveis* & \multicolumn{5}{c}{ \% do Custo Total } \\
\cline { 2 - 6 } & $\mathbf{S ~ ( 1 )}$ & \multicolumn{4}{c}{ S (2) } \\
\hline Máquinas e implem. & $\mathbf{1 1 7 , 2 0}$ & $\mathbf{1 1 7 , 2 0}$ & $\mathbf{3 5 0 , 8 4}$ & $\mathbf{4 2 8 , 7 0}$ & $\mathbf{5 2 2 , 1 4}$ \\
Sistema de irrigação & 17,43 & 13,05 & 11,57 & 11,10 & 10,21 \\
ITR & 0,00 & 17,03 & 15,09 & 14,47 & 13,32 \\
Custo alternativo & 0,00 & 0,00 & 0,00 & 0,00 & 0,00 \\
Custo Fixo Total (CFT) & 7,10 & 13,38 & 11,86 & 11,38 & 10,47 \\
\hline Acessórios máquinas e implementos & 24,53 & 43,47 & 38,51 & 36,95 & 33,99 \\
Mão-de-obra & 16,60 & 12,43 & 11,02 & 10,57 & 9,72 \\
Insumos & 4,61 & 3,45 & 3,06 & 2,93 & 2,70 \\
Despesas gerais/Administração & 40,64 & 30,44 & 26,97 & 25,88 & 23,81 \\
Despesas gerais/Pós-colheita & 2,52 & 1,89 & 1,67 & 1,61 & 1,48 \\
Energia & 6,84 & 5,12 & 5,49 & 5,96 & 6,11 \\
Água & 0,00 & 0,00 & 9,65 & 12,36 & 18,23 \\
Custo alternativo & 0,00 & 0,00 & 0,14 & 0,18 & 0,22 \\
Custo Variável Total(CVT) & 4,27 & 3,20 & 3,48 & 3,57 & 3,74 \\
\hline Custo total (CT) & 75,47 & 56,53 & 61,49 & 63,05 & 66,01 \\
\hline
\end{tabular}

\footnotetext{
*: CFT = custo fixo total; CVT = custo variável total e CT = custo total;

${ }^{*}:$ refere-se aos gastos com combustíveis, lubrificantes e reparos por hora de trabalho;

(Si): situação em que o produtor não possui o sistema de irrigação;

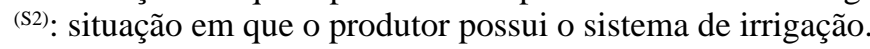


Entre as lâminas de água aplicadas (irrigação), houve uma diminuição da participação porcentual dos custos fixos e aumento da participação dos custos variáveis, à medida que a quantidade de água aplicada foi acrescida, refletindo em valores crescentes na produtividade de grãos. Os fatores que mais contribuíram para o aumento da participação dos custos fixos foram máquinas e implementos, para a situação (1) e sistema de irrigação para a situação (2).

Para a lâmina de $117,20 \mathrm{~mm}$, a situação (1) apresentou menor participação do custo fixo e maior participação do custo variável no custo total médio de produção.

Pela análise aqui apresentada verifica-se que a situação econômica da produção é muito dependente do preço de mercado e da tecnologia utilizada na produção. $\mathrm{O}$ grande problema do girassol era o preço de venda, costumeiramente baixo no Brasil. Porém, nos últimos anos esse cenário vem mudando, passando o preço da saca de $60 \mathrm{~kg}$ de $\mathrm{R} \$ 9,37 \mathrm{em}$ 2001, para R $\$ 31,80$ em 2004 (AGRIANUAL, 2002, 2005), com expectativa de valorização do girassol pelo aumento da demanda, influenciada pela recente política governamental de uso do biodiesel na matriz energética brasileira. Caso isto aconteça, provavelmente será ainda mais vantajoso a produção de girassol irrigado, na safrinha, na região de Lavras, MG.

\section{CONCLUSÕES}

Pelos resultados apresentados na análise feita neste trabalho e nas condições em que se desenvolveu o experimento e ao preço estimado para os insumos e do produto, ressaltam-se as seguintes conclusões:

Existe viabilidade técnica de produzir o girassol no cultivo de safrinha em Lavras, MG, em condições irrigadas e até mesmo de sequeiro;

$\mathrm{Na}$ condição de produtor irrigante o melhor manejo seria a aplicação da lâmina de 522,14 mm de água ao longo do ciclo;

Na condição do preço da saca de girassol considerada ( $\mathrm{R} \$ 31,80)$, a longo prazo o produtor deveria buscar outras alternativas de cultivo na safrinha, que seja mais rentável.

\section{REFERÊNCIAS BIBLIOGRÁFICAS}

AGRIANUAL. Anuário da agricultura brasileira. São Paulo: FNP Consultoria e Comércio, 2005. 536 p.

AGRIANUAL. Anuário da agricultura brasileira. São Paulo: FNP Consultoria e Comércio, 2005. 520 p.

CASTRO NETO, P.; SILVEIRA, J. V. Precipitação provável para Lavras, MG, baseada na função de distribuição de probabilidade gama III: períodos de 10 dias. Ciência e Prática, Lavras, v. 7, n. 1, p. 58-65, jan./jun. 1983.
EMPRESA BRASILEIRA DE PESQUISA AGROPECUÁRIA. Centro Nacional de Pesquisa de Soja. Informes da avaliação de genótipos de girassol 2001/2002 e 2002. Londrina, 2003a. 97 p. (Documentos, 226).

EMPRESA BRASILEIRA DE PESQUISA AGROPECUÁRIA. Centro Nacional de Pesquisa de Soja. Informes da avaliação de genótipos de girassol 2002/2003 e 2003. Londrina, 2003b. 87 p. (Documentos, 205).

FAGUNDES, M. H. Sementes de girassol:_alguns comentários. Disponível em: <h Acesso em: 10 out. 2002.

GOMES, E. M.; UNGARO, M. R. G.; VIEIRA, D. B. Influência da suplementação hídrica na altura de planta, diâmetro de capítulo, peso de sementes e produção de grãos. In: SIMPÓSIO NACIONAL DE GIRASSOL, 3.; REUNIÃO NACIONAL DA CULTURA DE GIRASSOL, 15., 2003, Ribeirão Preto. Anais... Ribeirão Preto: CATI, 2003. CD-ROM.

GOMES, E. M.; UNGARO, M. R. G.; VIEIRA, D. B. Produção de grãos, óleo e proteína em girassol sob estresse hídrico. In: SIMPÓSIO NACIONAL DE GIRASSOL, 4.; REUNIÃO NACIONAL DA CULTURA DE GIRASSOL, 16., 2005, Londrina. Anais... Londrina: Embrapa Soja, 2005. p. 23-25.

REIS, R. P. Fundamentos da economia aplicada. Lavras: UFLA/FAEPE, 2002. 91 p.

SILVA, A. G. da; MORAES, E. B. de; PIRES, R.; CARVALHO, C. G. P. de; OLIVEIRA, A. C. B. de. Efeito do espaçamento entre linhas em três híbridos de girassol. In: REUNIÃO NACIONAL DE PESQUISA DE GIRASSOL, 16.; SIMPÓSIO NACIONAL SOBRE A CULTURA DO GIRASSOL, 4., 2005, Londrina. Anais... Londrina: Embrapa Soja, 2005. p. 86-88.

SILVA, M. N. da. A cultura do girassol. Jaboticabal: FUNEP-UNESP, 1990. 67 p.

SILVA, M. R.; UNGARO, M. R. G.; RAMOS, N. P.; AGUIAR, R. H. Cultivo de girassol em Lucianópolis: estudo de caso. In: REUNIÃO NACIONAL DE PESQUISA DE GIRASSOL, 16.; SIMPÓSIO NACIONAL SOBRE A CULTURA DO GIRASSOL, 4., 2005, Londrina. Anais... Londrina: Embrapa Soja, 2005. p. 68-70.

UNGARO, M. R. G. Girassol (Helianthus annuus L.). Boletim Informativo do Instituto Agronômico, Campinas, v. 200, p. 112-113, 1990. 